This is a reviewed article

\title{
Public Pedagogy and the City
}

\section{Museums, Libraries, and Cultural Centers as Sites for Multicultural Education}

Galina Shavard

Oslo and Akershus University College of Applied Sciences

Galina.Shavard@hioa.no

Keywords:

multicultural education

public pedagogy

public education

Norway

Russia 


\begin{abstract}
This paper seeks to contribute to the interdisciplinary discussion of the all-too-oftencontested concept of multicultural education and, specifically, the way it is conceptualized and put into practice in city libraries, museums, cultural centers, and other emerging sites of public education. As the formal education system has so far been seen as the main venue for research on multicultural education, to date there is relatively little empirical inquiry exploring how the ideas of multicultural education play out outside the school settings. The study aims to address this gap and explore the educators' perspective, the views of those who set the agenda for educational programs. Based on 10 in-depth interviews with the educators in Oslo and Moscow, two cities with extensive networks of public education, the study sheds light on how multicultural education is interpreted in this often-overlooked context. Drawing on the transformative approaches in multicultural education on the one hand and the concept of public pedagogy on the other, the discussion uncovers some of the potentials and limitations intrinsic to the practices of multicultural education in the settings of public education.
\end{abstract}




\section{Introduction}

Today, the overwhelming majority lives in large, socially segregated cities. They charm with endless opportunities and jazzy diversity but in return offer little sense of belonging as it has been traditionally understood - global shift from rural to urban in the 20th century had critical consequences for how we live, work, and interact with one another. At first sight, it may seem as if, driven by accelerated globalization, world cities and their contemporary way of life now look more uniform than ever before. However, at the same time, cities are rapidly growing more diversified in terms of economic, ethnocultural, sexual, and other types of identities. In fact, these parallel trends of increasing cultural sameness and interconnectedness on the one hand and pluralization and sophistication of identities on the other are not mutually exclusive (Appadurai, 2001; Bauman, 2013; Pieterse, 2009). The interplay between the two is reflected in the social dynamics of the cities and translates into the market- and technology-fueled homogeneity as well as into the progressive diversification and often segregation in urban communities.

Indeed, intensified diversity has become a new reality, and it is not just a setting but also a driver for prosperity and a source of tension (Putnam, 2007). Such developments challenge cities to become the places where peaceful multicultural encounters can occur in a variety of public contexts and where new types of cultural production can take place. In this regard, the issue of the quality of life in a multicultural city has become most current and, more specifically, the question of how social institutions can better accommodate and "digest" not only this increasing cultural diversity but also, and often closely connected to it, socioeconomic inequality. A strategic element of the integration policies that aim for such accommodation is the provision of multicultural education, and schools and kindergartens have so far rightfully been viewed as the main arena for multicultural education as well as critical sites for research (Banks \& Banks, 2009). Relatively few empirical studies, however, have been conducted to explore how the ideas of multicultural education "spill over" into the domain of public education.

In this paper, I will view museums, libraries, cultural centers, and other emerging urban spaces as the sites of public education. By drawing on the ideas of public pedagogy (Burdick, Sandlin, \& O'Malley, 2013; Mayo, 2013) and transformative approaches in multicultural education (Banks \& Banks, 2009), I will explore how educators and program directors in these organizations understand and operationalize the concept of multicultural education. In what follows, I first frame the theoretical perspective and account for the research design of the study. I will then present the discussion of the findings and concluding thoughts.

\section{Theoretical Perspective}

The theoretical perspective that will frame the discussion draws on Banks's (2009) model of four approaches to multicultural education, Bhabha's (2003) concept of "the right to narrate" and the concepts of public pedagogy and bridging social capital.

\section{A Contested Concept of Multiculturalism}

In 1996, UNESCO published a report "Education for the Twenty-First Century" (Delors, 1996), where it is particularly stressed that in the era of intensified globalization and mobility, extra attention needs to be given to "learning to live together" as a foundational value and skill. All other forms of learning, such as learning to know, learning to act, and learning to be, are in effect the primary pillars supporting that most critical one (Delors, 1996, 2013). What we now call multicultural education-a central concept in the "learning 
to live together" agenda-originated in the $60 \mathrm{~s}$ in the wake of the civil rights movement as a corrective to a long-standing de facto policy of assimilating minority groups into the "melting pot" of mainstream US culture. The ideas of multicultural (in Europe often referred to as intercultural) education have since then spread around the world, localized, and become a contested and highly politicized battleground (Coulby, 2006).

In the early 21 st-century Europe, scholarship addressing education in multicultural contexts has taken place within a broader political context often rather hostile to the whole concept of multiculturalism. Moreover, we see a sharp increase in Islamophobic and far-right extremism and hate speech. Prominent European political figures "have attacked multiculturalism claiming that 'state multiculturalism' undermines community and asserting that multiculturalism has 'failed utterly' and that locals and foreign workers cannot 'live happily side by side'" (Osler, 2015, p. 16).

The academic debate on the benefits and risks of contemporary multicultural communities and the contribution multicultural education can and cannot make is also rather heated. It can be illustrated with a fragment from a seminal lecture by Robert Putnam (2007, p. 137) in which he claims "that the most certain prediction that we can make about almost any modern society is that it will be more diverse a generation from now than it is today." He argues that in the long run, immigration and diversity are most likely to bring cultural, economic, fiscal, and developmental advantages. Yet, in the short term, immigration and ethnic diversity tend to reduce generalized trust and social capital (Putnam, 2007, p. 138). Putnam (2007) further predicts that in the remote future, successful mixed societies will have overcome fragmentation by creating new, cross-cutting forms of social solidarity, intercultural communication, and more encompassing identities. However, the diversity is not just ethnic. There is also an increased diversity as a result of individualization and pluralization processes (Bauman, 2013; Putnam, 2007), and the disappearance of old forms of social integration entails the development of new social dynamics and patterns.

The cities are the centers of a constant flow of people-here, globalization erodes the distinctions between permanent and temporary migrants, between economic migrants and asylum seekers, and between countries of origin and countries of destination. Some see the thrill and positive energy in those changes; others have considerable doubt about the idea of a multicultural society as an enriching experience for everyone. An encounter with diversity is often experienced as an encounter with otherness and strangeness and is characterized by ambivalence, feeling of unease, anguish, and disorientation. These experiences are socially situated and depend on the way otherness is perceived in the community: as an acute threat to the national identity or as a vital resource (Vandenabeele, 2012). In many cases, contact with unfamiliar ways of life and expression can stimulate a positive feeling of grasping, wonder, and fascination (which it does when one goes traveling, for example). It is this very excitement that is commonly related to the magic and vibe of cities and that sites of public education often thrive on.

Putnam (2007) sees two ways of looking at how multicultural communities process diversity. On the one hand, contact theory states that diversity reinforces interethnic tolerance and social solidarity, meaning that as we have more contact with people who are unlike us, we overcome our initial hesitation and ignorance and come to trust them more. In contrast, so-called conflict theory suggests that for various reasons-but above all, contention over limited resources-diversity fosters out-group distrust and in-group solidarity. In other words, the more we are brought into physical proximity with people of another race or ethnic background (or of another religion or different basic values), the more we stick to "our own" and the less we trust "the other" (Putnam, 2007). In this regard, it is important to draw a distinction between "bonding" social capital, that is ties to people who are like us in some important way (the most traditional way of togetherness), and "bridging" social capital, that is ties to people who are unlike us in some important way 
(Putnam, 2007). The sites of public pedagogy, specifically the ones occupied with the practices of multicultural education, are underpinned by these ideas of contact theory and bridging social capital.

This way, in spite of populist proclamations of politicians, the ideas of multicultural education have not only developed significantly further since the 60 s but also "spilled over" into social life and been taken up by the institutions and sites of public education.

\section{Perspectives on Multicultural Education}

Globally, many multicultural educators draw for inspiration on the substantial theoretical work of James Banks, who since the 1960s has conducted pioneering work, most recently in the field of education for democracy and diversity in an age of globalization (Banks, 2006). Banks's framework of four approaches to multicultural education (discussed further in more detail) has been commonly used in the school setting but, as I will argue here, has the potential to be applied as a broader analytical lens to the sites of public pedagogy: libraries, cultural centers, museums, and other emerging places as they are often hybrid and combine educational, cultural, and social agendas. Just like schools, they engage with a selection of the cultures and knowledge base of the society. Their case is, therefore, similar to that of the school curriculum (Mayo, 2013). Cultural and educational programs in the major museums, libraries, and cultural centers, just like the ones in schools, reflect what counts and what does not count as valid knowledge and culture (Apple \& Aasen, 2003). However, unlike schools, the institutions of public pedagogy are not bound by top-down state curriculum or the pressures of the market and therefore have more power to select and legitimize (or marginalize) the content of their programs (Borg \& Mayo, 2010). This way, it can be argued that as educational sites are nowadays multiple and reach far beyond the schooling system, it is possible to apply Banks's critical perspective in the settings that rarely feature in the literature on multicultural education-sites of public pedagogy.

The first approach in Banks's framework for multicultural education is contributive. It reflects the least involvement in multicultural education and may, in the case of public pedagogy, refer to the incorporation of selected activities that celebrate and often exotify holidays, heroes, and special events from folk and ethnic cultures (importantly, the ones that are not in conflict or competition with the mainstream culture). In the second, additive approach, the content, concepts, themes, and perspectives are added to the educational programs, although without changing the latter's monocultural ideology and structure. The third, transformative approach challenges the structure of the educational program and encourages viewing concepts, issues, themes, and problems from several perspectives. Finally, the social-action approach upgrades the transformative approach with activities to strive for social change and equity.

A related perspective within the transformative and social-action approaches which is of particular relevance for public pedagogy is Bhabha's concept of "the right to narrate" (Bhabha, 2003). Bhabha suggests that the inclusion of personal stories in education allows one to find a place of one's own within an inclusive collective history. Drawing on this idea, Osley (2015), argues that to ensure the right to narrate essentially means to implement a range of democratic imperatives: it assumes an equitable access to those institutionsschools, universities, museums, libraries, theatres-that give one a sense of a collective history and the means to convert those resources into a narrative of one's own. In support of applicability of Banks's framework to public pedagogy, Bhabha (2003) claims that schools cannot act alone and maintains that such an empowered sense of "selfhood" and belonging depends on a public culture in which one is certain that his/her story will be heard and acted upon. In turn, this depends on society's willingness to provide and reinforce "the right to take part in cultural life," and among other means through education in the formal 
schooling settings as well as in the educational contexts outside school, in what Henry Giroux (2011) calls "sites of public pedagogy."

\section{Sites of Public Pedagogy}

Premised on Paulo Freire's and John Dewey's democratized and broad concept of education, these public pedagogic sites range widely from schools to libraries, museums, cinemas, and cultural centers but, in a contemporary city, can include a multitude of other classical and emerging hybrid formats (Burdick et al., 2013; Sandlin, Schultz, \& Burdick, 2010). Giroux (2005) applies the term public pedagogy primarily to critique the mainstream ideology and devastating side effects of neoliberal policies when arguing that universities, schools, and other learning sites should serve first and foremost as democratic public spaces. This vision of education as a lever for social transformation and action is inherently in accord with Banks's framework of multicultural education.

In a contemporary city, even traditional social and cultural institutions are far from monolithic, and this certainly applies to the museums, libraries, and other sites of public education. While these institutions can play a part in cementing cultural hegemony, they are also agents of the renegotiation of hegemonic relations through public pedagogies. Like schools, the sites of public education are culturally selective and often decontextualize artefacts by extricating them from their original environment. They could, however, be conceived of (in the way in which Freire, Giroux, Mayo, and other critical thinkers conceive of schools and other institutions) as sites of contestation, transformation, and reconstruction (Biesta, 2012; Giroux, 2001; Mayo, 2013). Adding to this line of thought, Groiss (2012) also argues that while participation in public life consists to a great extent in interaction, cooperation, and mild confrontation, in the first place, it is found in the experience of exposure and public self-display, and it is through this exposure that we become part of a community. The earlier-mentioned concept of "the right to narrate" seems to be located within a similar line of thinking.

Drawing on the theoretical perspectives of the transformative and social-action approaches in public pedagogy, the potential of public pedagogy to build bridging capital and ensure "the right to narrate," I will further explore how the concept of multicultural education is interpreted and acted upon in the settings of public education from the perspective of educators. However, I will first briefly account for the research design of the study.

\section{Research Design and Methods}

This paper is based on a small-scale qualitative study conducted as a part of a master's degree in Multicultural and International Education at Oslo and Akershus University College of Applied Sciences, Norway. The project is based on the data from ten semi-structured indepth interviews with the educators whose primary responsibility was setting the agenda for the public educational program in major city museums, libraries, cultural centers, and other emergent sites of public pedagogy. Oslo and Moscow were chosen partly because of the similarities in the approach to public education and partly because of the researcher's familiarity with the contexts. Despite apparent political and socioeconomic differences, the cities have important common characteristics: both have extensive networks of state-run libraries, museums, and cultural centers as well as a similar landscape of emerging edupreneurship projects (for instance, such international entrepreneurial projects in education as ScienceSlam, PechaKucha, and CourseraLab run in both Oslo and Moscow). Accordingly, the choice of sample places and participants was guided by their overall visibility and popularity in the cultural and media landscape. The data were gathered during the autumn of 2013. 
Six of the hour-long interviews took place in Moscow and four in Oslo (see overview of the informants and sites in Table 1 below); they were recorded, transcribed and translated into English. The interview guide was based on the questions regarding informants' understanding of the role of public education in the city and the potential and limitations of multicultural education in public pedagogy settings. Attention was also paid to eliciting specific vignette stories that could illustrate the informants' vision with concrete examples from practice. I also conducted supplementary observations of public lectures, debates, and other public educational events in the sampled sites prior to the data collection in order to get a better understanding of the context and prepare for the interviews. (In this relation, of relevance was a public conference called "Hvorfor trenger vi Litteraturhuset" ["Why do we need the House of Literature?"] that allowed me to scan the most current ideas and opinions around public education in Oslo in preparation for the interviews). The data analysis was guided by a combination of theoretical concepts related to critical pedagogy and naturally emerging themes. The names of informants are not given in the study; however, below is an overview of the concrete sites and the informants' positions.

\begin{tabular}{|c|c|c|c|}
\hline Informants & Position & Site & Type of Organization \\
\hline Informant 1 & Program director & $\begin{array}{l}\text { The House of Literature } \\
\text { (www.litteraturhuset.no), Oslo }\end{array}$ & Foundation \\
\hline Informant 2 & Program director & $\begin{array}{l}\text { Oslo Bymuseum (Intercultural } \\
\text { Museum and Oslo City Museum, } \\
\text { www.oslomuseum.no), Oslo }\end{array}$ & State-owned \\
\hline $\begin{array}{l}\text { Informant } 3 \text { and } \\
4\end{array}$ & $\begin{array}{l}\text { Local library } \\
\text { directors }\end{array}$ & $\begin{array}{l}\text { Deichmanske Library } \\
\text { (www.deichman.no), Oslo }\end{array}$ & State-owned \\
\hline Informant 5 & $\begin{array}{l}\text { Development } \\
\text { director }\end{array}$ & $\begin{array}{l}\text { Russian State Library for Young } \\
\text { Adults (www.rgub.ru), Moscow }\end{array}$ & State-owned \\
\hline Informant 6 & Program manager & $\begin{array}{l}\text { Strelka Institute (cultural center, } \\
\text { www.strelka.com), Moscow }\end{array}$ & Private \\
\hline Informant 7 & Director & $\begin{array}{l}\text { ZIL Cultural Centre (www.zilcc.ru), } \\
\text { Moscow }\end{array}$ & State-owned \\
\hline Informant 8 & Program director & $\begin{array}{l}\text { Polytechnic Museum, } \\
\text { (www.pmlectures.ru), Moscow }\end{array}$ & State-owned \\
\hline Informant 9 & Program director & $\begin{array}{l}\text { Public Program at Higher School of } \\
\text { Economics, (www.hse.ru }) \text {, Moscow }\end{array}$ & State-owned \\
\hline Informant 10 & Program director & $\begin{array}{l}\text { Digital October (flagman projects: } \\
\text { PechaKucha and Coursera Hub; } \\
\text { www.knowledgestream.ru), } \\
\text { Moscow }\end{array}$ & Private \\
\hline
\end{tabular}

Table 1: Overview of the informants and sites. 


\section{Discussion}

The presentation and discussion of the findings are organized around four themes, namely, the ideas related to the craft of "building bridges" in the all-too-often unstable and hostile social terrains; simultaneous development "going global" and "going local" in contemporary spaces of public education; insufficiency of multicultural agenda if you fail to bring people together; and I finally wrap up the discussion with presenting two examples of social action approach in multicultural public pedagogy.

\section{Building Bridges}

Largely in accordance with Putnam's concept of bridging social capital, "a bridge" was a metaphor that was often used by the informants to elaborate on what multicultural education can achieve in public education settings. This metaphor was often applied to refer to the concepts of social cohesion and a sense of belonging:

The goal to contribute to the social cohesion of the society may sound too big [for public education settings], but it is common cultural and educational experience that brings cultures, social classes, and other groups together. (Interview, Moscow, September 2013)

This extends the objective of public education from conservation and enlightenment to the construction of bridging social capital. It also points to transformative and social-action objectives:

By the society, we are expected to be more than just a museum. However, while we are bound by social challenges, we are free in the way we address them. (Interview, Oslo, December 2013)

Unlike [big national] museums that target a wider and irregular audience of tourists (i.e., people that come only once), we are a local space in every way. Moreover, we have no choice but to relate to the reality of diversity. We have to think seriously of how to attract the audience that reflects the social landscape. (Interview, Oslo, November 2013)

\section{Going "glocal"}

The last two quotes highlight a distinction between a classic cultural institution like the museum of ancient history or the opera house, that may well exist in a vacuum, detached from the city, and a local library or museum that is embedded in the community and is therefore expected to reflect its changes. In other words, one may argue that while big national museums internationalize and become an element of a global landscape, many other traditional institutions, such as libraries and smaller museums, in contrast deliberately "localize" by extending the scope of functions and giving space for a more transformative approach. These ideas of transformative and social-action approaches were stressed by the informants in Oslo and Moscow:

We think that the mission of museums is not just to conserve but to communicate with the visitors and the community. We try to create such a community by not simply sharing the knowledge but situating it locally and making our museum a place for socializing. We expect feedback, reaction, we want involvement. In this sense, a multicultural educational program is the most efficient tool for building a community. (Extracted from the recording of an observed lecture, Moscow, February 2014) 


\section{Why multicultural agenda is not enough}

An important element of transformative public education often highlighted in the interviews was the need to bring different people physically together, to create the feeling of exposure, co-presence, and a shared experience:

I feel that there is a strong need to bring people together, the need to be together simultaneously, see things happening live and be a part of the public debate. (Interview, Oslo, November 2013)

The efforts to create a shared experience were sometimes illustrated with collaboration projects between public and formal education:

[To create a shared experience,] we take one kindergarten in the east of Oslo [where most parents of non-Norwegian background reside] and one from the west and mingle them in our workshops. But it is fairly easy to arrange with schools and kindergartens. It requires much more effort and thought [to arrange] multicultural education activities targeted at adults. (Interview, Oslo, November 2013)

\section{Many Faces of Diversity}

However, the way in which the informants reflected on multicultural education practices and, specifically, engagement with diversity differed. In the case of Oslo, the informants seemed to be more open-minded when discussing current social challenges and were also more specific in the description of how they work for better accommodation of diversity. It was easier for them to come up with concrete cases in which a common theme was the inclusion of new, often neglected or underrepresented, narratives:

We cannot change people, but we try to create a climate that can make people more accepting and receptive to each other's stories. With such a thought in mind, we plan this winter, for example, to talk about the Roma community in Oslo providing not just a historical perspective but a deeper discussion drawing from the current voices, dilemmas, and narrative of real families living here. (Interview, Oslo, December 2013)

As the concept of multicultural education was often interpreted broadly by the informants, far beyond ethnic and cultural differences, "the right to narrate" was extended to those who are invisible by the society for reasons other than immigrant background:

An example of how we try to connect better with the local community and represent its diversity is through emotional involvement. For example, the exhibition we have about the Norwegian women married to German soldiers during the time of occupation in WW2. It is highly sensitive and even bordering on tabooed, but every day, we have elderly women sitting in the exhibition halls quietly together. It feels like more than just conservation of history ... It's something more; it's healing. (Interview, Oslo, December 2013)

The two above cases illustrate how public pedagogy tries to reach out to the most sensitive narratives of the local community, the issues that the formal schooling system would rarely dare to touch. Overall, multicultural education seemed to be perceived by the informants as more successful if it began with the self and the family: it was deemed to build self-esteem and contribute to a stronger and more nuanced and critical sense of belonging. 
By contrast, recently booming public-education activities in the museums, cultural centers, and libraries in Moscow seemed to address either the social groups with already wellaccumulated cultural capital and agency or exercise a version of contributive and additive approaches according to Banks's framework. While the need to focus on more inclusive and transformative educational practices was certainly well-articulated, the informants in Moscow came up with few concrete examples to illustrate how they put this vision of inclusive and multicultural education into practice. One of the informants noted the following:

Whereas there are some isolated cases of inclusive educational programs for families from disadvantaged backgrounds, there is hardly any case of a successful or promising project for example for immigrants or elderly citizens in Moscow, two very vulnerable groups. (Interview, Moscow, September 2013)

What we see as a common practice in the field of social development in Russia is what I may call "unintentional segregation." It is when money goes to the social events (concerts, workshops, public lectures) targeted only at vulnerable groups: orphans, immigrant families, or other disadvantaged groups. While all these activities are well intended, they do nothing for the integration and inclusion into the wider society. We would like to seek a different sort of energy-of togetherness rather than one based on compassion. (Interview, Moscow, August 2013)

The next vignette, while seemingly having no relation to multicultural education, shows the common attitude and provides some context to mainstream thinking:

Several years ago, we received funds to re-design the library so that it would be adapted to people with different physical abilities. We were not the first library to do so in Moscow, but we had very little experience and went to visit other libraries in Russia that claimed to be friendly to people with limited mobility. One such library that we visited had no ramps. This fact puzzled us at the beginning, but the explanation was simple. The programs for mobility-challenged visitors did not intend that they come over: books were delivered to homes and picked up later by the staff. It was a well-meant, expensive, and seemingly convenient solution for everyone. However, this is not the idea we have in mind. We want people to come here and share the same space, see each other. (Interview, Moscow, August 2013)

\section{Public Multicultural Education and Transformative Pedagogy}

While the latter story is not an issue of cultural diversity, it is nevertheless a case of diversity and inclusiveness of public education in a broader democratic sense as it was understood by the informants. In this regard, two examples of multicultural public pedagogy observed during the field trip are worth mentioning, as they relate more closely to cultural diversity and point to the potential of multicultural education in public-education settings.

During the summer season of 2013, the ministry of culture in Moscow ran free language courses in some of the museums and libraries in the city. The languages were the ones that are most common for the labor immigrants in Moscow, such as Azerbaijani, Kazakh, and the Lezgic-family languages. The underlying idea was to initiate interest in immigrant cultures and contribute to the building of a more inclusive society. The project ran with tremendous success, notably not only among Russian speakers but also among native speakers since many of them came as volunteer language assistants or simply joined out of curiosity.

Another initiative of a social-action approach in multicultural education that runs in the libraries and cultural centers of both Oslo and Moscow is the Human Library Project. It is a 
global project designed to build a positive framework for conversations that can challenge old and current stereotypes and prejudices in the society. It uses the language and mechanism of a library and the methodology of public pedagogy to facilitate respectful dialogue that can positively impact the attitudes and behaviors towards the members of communities that are often at risk of exclusion and marginalization. Organizers invite those who wish to volunteer as "books," and participants in the event can "read" these books that is, listen to the stories and ask questions in a one-to-one conversation. During the time of data collection, the "books" in Moscow were, for instance, a gay couple, a labor immigrant from Uzbekistan, and a municipality politician; in Oslo - a housewife, a Roma woman, and a Polish immigrant. In a way, these events bear some resemblance to speed dating, without the "dating" itself, of course. Of interest is that in May 2015, the Human Library in Moscow received support from the Research Centre for Migration and will now pilot the project in schools, thus extending transformative multicultural education to formalschooling settings.

Ultimately, the educators' perspective on multicultural education in the settings of museums, libraries, cultural centers, and other sites of public pedagogy showed a significant potential for the further development of the ideas of transformative and social-action approaches. This development appears to be rooted in the collaboration between formal and public education, the inclusion of diversity through personal and familial narratives, and the emphasis on multicultural practices that create a common experience without exotification or turning multicultural education into a one-way street.

\section{Concluding Thoughts}

In the introduction of Exhibiting Cultures, Karp (2012) suggests that in order to be powerful agents of multicultural education, museums must let go of the metaphor of the museum as a temple and adopt the concept of a museum as a forum. As the data suggest, this idea can be extended to libraries and other traditional and emerging sites of public culture and education. To be forums rather than temples, these places have to tell stories and encourage dialogue, include diverse narratives, build strong social bridges, and create a shared experience. This development of the sites of public pedagogy as democratic spaces that allow diverse stories to emerge, get exchanged, appropriated, and negotiated is about enabling visitors to become subjects in a process of participation. The key challenges here, as the informants recurrently pointed, lie in the attraction of diverse audience and in balancing cultural sensibilities-themes that would on the one hand critically engage people but at the same time not estrange them as too radical. This way, with a discussion at the intersection of multicultural education and public pedagogy, I have tried to show how sites of public education can assume the agency as sites for the transformative and social-action approaches to multicultural pedagogy - the sites in which, as Freire famously noted, "people can learn to read the world critically." 


\section{References}

Appadurai, A. (2001). Globalization. Duke University Press. http://dx.doi.org/10.1215/9780822383215

Apple, M. W., \& Aasen, P. (2003). The state and the politics of knowledge. Psychology Press. http://dx.doi.org/10.4324/9780203441190

Banks, J. A., \& Banks, C. A. M. (2009). Multicultural education: Issues and perspectives. John Wiley \& Sons.

Bauman, Z. (2013). Liquid modernity. John Wiley \& Sons.

Biesta, G. (2012). Becoming public: Public pedagogy, citizenship and the public sphere. Social \& Cultural Geography, 13(7), 683-697. http://dx.doi.org/10.1080/14649365.2012.723736

Borg, C., \& Mayo, P. (2010). Museums: Adult education as cultural politics. New Directions for Adult and Continuing Education, 2010(127), 35-44. http://dx.doi.org/10.1002/ace.379

Burdick, J., Sandlin, J. A., \& O’Malley, M. P. (2013). Problematizing public pedagogy. Routledge.

Coulby, D. (2006). Intercultural education: Theory and practice. Intercultural Education, 17(3), 245-257. http://dx.doi.org/10.1080/14675980600840274

Delors, J. (1996). Learning: The treasure within: Report to UNESCO of the International Commission on Education for the Twenty-first Century (Century International Commission on Education for the Twenty-First). Unesco Pub.

Delors, J. (2013). The treasure within: Learning to know, learning to do, learning to live together and learning to be; What is the value of that treasure 15 years after its publication? International Review of Education, 59(3), 319-330. http://dx.doi.org/10.1007/s11159-013-9350-8

Dewey, J. (2007). Experience and education. Simon and Schuster.

Freire, P. (2014). Pedagogy of the oppressed: 30th anniversary edition. USA: Bloomsbury Publishing.

Giroux, H. A. (2001). Public spaces, private lives: Beyond the culture of cynicism. Rowman \& Littlefield.

Giroux, H. A. (2011). On critical pedagogy. USA: Bloomsbury Publishing.

Groiss, B. (2012). Publichnoe prostranstvo: Ot pustoti k paradoxu [Public space: From emptiness to paradox]. Moscow: Strelka Press.

Karp, I. (2012). Exhibiting cultures: The poetics and politics of museum display. Smithsonian Institution.

Mayo, P. (2013). Museums as sites of critical pedagogical practice. Review of Education, Pedagogy, and Cultural Studies, 35(2), 144-153. http://dx.doi.org/10.1080/10714413.2013.778661

Osler, A. (2015). The stories we tell: Exploring narrative in education for justice and equality in multicultural contexts. Multicultural Education Review, 7(1-2), 12-25. http://doi.org/10.1080/2005615X.2015.1048605

Pieterse, J. N. (2009). Globalization and culture: Global mélange. Rowman \& Littlefield Publishers.

Putnam, R. D. (2007). E pluribus unum: Diversity and community in the twenty-first century; The 2006 Johan Skytte Prize Lecture. Scandinavian Political Studies, 30(2), 137-174. http://dx.doi.org/10.1111/j.1467-9477.2007.00176.x

Sandlin, J. A., Schultz, B. D., \& Burdick, J. (2010). Handbook of public pedagogy: Education and learning beyond schooling. Routledge. 
Vandenabeele, J. (2012). Learning in multicultural cities. International Journal of Lifelong Education, 31(1), 1-3. http://dx.doi.org/10.1080/02601370.2012.636566 